\title{
Radiofrequency Ablation versus Cryoablation in the Treatment of Paroxysmal Atrial Fibrillation: A Meta-Analysis
}

\author{
Ali H. Hachem, ${ }^{1}$ Joseph E. Marine, ${ }^{2}$ Housam A. Tahboub, ${ }^{1}$ Sana Kamdar, ${ }^{1}$ \\ Shaffi Kanjwal, ${ }^{1}$ Ronak Soni, ${ }^{1}$ and Khalil Kanjwal $\mathbb{D}^{3}$ \\ ${ }^{1}$ Central Michigan University, College of Medicine, Mt. Pleasant, MI, USA \\ ${ }^{2} J o h n$ 's Hopkins Institute, Baltimore, MD, USA \\ ${ }^{3}$ Mclaren Cardiovascular Group, Michigan State University, East Lansing, MI, USA
}

Correspondence should be addressed to Khalil Kanjwal; khalilkanjwal@yahoo.com

Received 8 October 2017; Accepted 17 January 2018; Published 1 April 2018

Academic Editor: Syed Wamique Yusuf

Copyright $(92018$ Ali H. Hachem et al. This is an open access article distributed under the Creative Commons Attribution License, which permits unrestricted use, distribution, and reproduction in any medium, provided the original work is properly cited.

Background. Pulmonary vein isolation is commonly performed using radiofrequency energy with cryoablation gaining acceptance. We performed a meta-analysis of randomized controlled trials which compared radiofrequency versus cryoablation for patients with atrial fibrillation. Methods. A systematic search strategy identified both published and unpublished articles from inception to November 10, 2016, in multiple databases. The primary outcomes for this meta-analysis were long-term freedom from atrial fibrillation at 12-month follow-up and overall postoperative complication rates. For all included studies, the methodological quality was assessed through the Cochrane Collaboration's tool for risk of bias. Results. A total of 247 articles were identified with eight being included in this review as they satisfied the prespecified inclusion criteria. Overall, there was no significant difference in freedom from atrial fibrillation at $\geq 12$-month follow-up between those receiving cryoballoon and radiofrequency ablation, respectively $\left(\mathrm{OR}=0.98, \mathrm{CI}=0.67-1.43, I^{2}=56 \%, p=0.90\right)$. Additionally, the secondary outcomes of duration of ablation, fluoroscopy time, and ablation time failed to reach significance. Cryoballoon ablation had significantly greater odds of postoperative phrenic nerve injury at 12-month follow-up. Conclusions. Our meta-analysis suggests that cryoballoon ablation provides comparable benefits with regard to freedom from atrial fibrillation at medium-term follow-up, fluoroscopy time, ablation time, operative duration, and overall complication rate in comparison to radiofrequency ablation.

\section{Background}

Atrial fibrillation $(\mathrm{AF})$ is a common arrhythmia affecting up to $2 \%$ of the general population $[1,2]$. AF commonly affects the elderly and is associated with a $26 \%$ lifetime risk in males and $23 \%$ lifetime risk in females by age 80 [3]. Patients with AF have increased mortality and increased risk of stroke. In addition to that, there is an increased risk of various cardiac complications, including myocardial ischemia/infarction and congestive heart failure exacerbation and dementia [4].

The first line therapy for AF includes the use of pharmacological agents, aiming at rate control, rhythm control, and anticoagulation; however, the recurrence rate with antiarrhythmic drugs is still high and side effects of these medications require close monitoring $[4,5]$. The standard treatment for patients with paroxysmal drug refractory AF is catheter ablation via pulmonary vein isolation. Catheter ablation has emerged as the most effective rhythm control strategy. Catheter ablation is differentiated by the energy source used. The two current modes of energy being used are radiofrequency and cryothermal energy [4].

Radiofrequency ablation (RFA) causes tissue damage using heat while cryoablation causes tissue damage by freezing the target region. RFA has been considered to be the standard technique and is utilized more frequently than cryoablation. However, it is time consuming, requires extensive training, and is associated with an increased risk of cardiac perforation, thromboembolism, and pulmonary vein stenosis [5-7]. Cryoablation, using a cryoballoon catheter, is gaining acceptance as being equally as effective as RFA with potentially decreased rates of complications, although there has been a higher reported rate of phrenic nerve palsy $[5,8,9]$. 
TABLE 1: Search strategies.

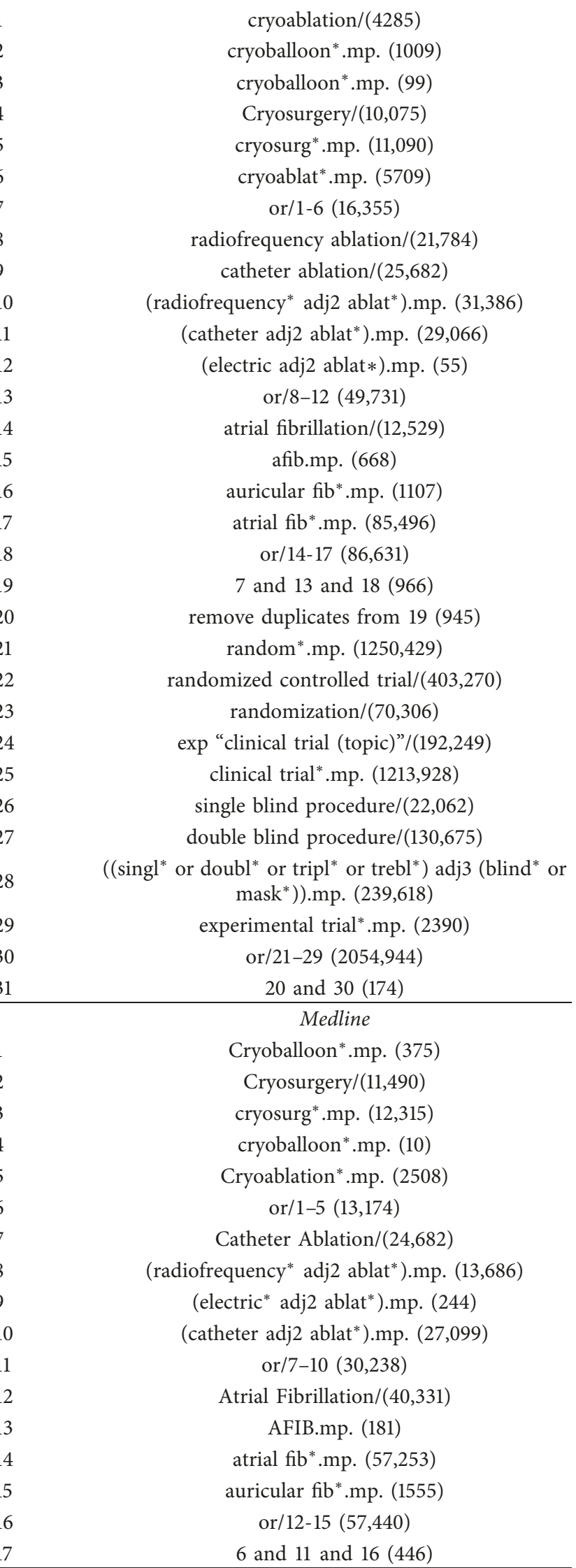

TABle 1: Continued.

\begin{tabular}{lc}
\hline 18 & remove duplicates from $17(441)$ \\
19 & randomized controlled trial/(416,221) \\
20 & Randomized Controlled Trials as Topic/(103,492) \\
21 & Random Allocation/(86,790) \\
22 & controlled clinical trial/(90,701) \\
23 & experimental trial*.mp. $(2040)$ \\
24 & Single-Blind Method/(21,827) \\
25 & Double-Blind Method/(135,430) \\
26 & ((singl* or doubl* or tripl* or trebl*) \\
27 & adj3 (blind* or mask*).mp. $(196,284)$ \\
28 & randomized controlled trial.pt. $(416,221)$ \\
29 & clinical trial.pt. $(500,017)$ \\
30 & rct*.mp. $(26,020)$ \\
31 & random*.mp. $(1028,478)$ \\
32 & exp clinical trial/(737,112) \\
33 & clinical trial*.mp. $(852,720)$ \\
34 & exp Clinical Trials as Topic/(292,379) \\
35 & or/19-33 (1567,877) \\
\hline
\end{tabular}

While catheter ablation is the mainstay for treatment of AF, the optimal method of ablation is currently under debate. Prior meta-analyses on the topic have been conducted, but they were either inconclusive or included a wide array of study designs, thereby limiting their overall quality and external validity. The overall goal of this metaanalysis is to compare the long-term effectiveness, as measured by freedom from atrial fibrillation at 12-month follow-up, and the complications in treating adult patients ( $\geq 18$ years old) with atrial fibrillation, using these two methods.

\section{Methods}

2.1. Criteria of Study Inclusion. All studies that randomly allocated adult patients ( $\geq 18$ years old) to receive either cryoballoon or radiofrequency ablation for atrial fibrillation were considered for eligibility. Authors of studies for which the randomization sequence or generation tool was unknown were contracted for clarification. Finally, quasi-randomized studies were also considered for eligibility if there was mention of a quasi-random method of allocation such as by date, case number, or date alteration. Nonrandomized studies were excluded to limit overall heterogeneity and improve internal validity of the results.

2.2. Search Methods for Identification Studies. A search strategy was created to identify both published and unpublished articles from inception to May 10, 2016, in the following databases: MEDLINE, Embase, Cochrane Library, and the Database of Abstracts of Review of Effects (DARE). The full search strategy can be viewed in Table 1; however, briefly, the terms of the search related to cryoballoon, catheter ablation, radiofrequency, and cryoablation. The 
results generated by the search strategy were reviewed and screened. The initial agreement between the reviewers based on full-text eligibility was assessed through the calculation of an unweighted kappa $(\kappa)$. As per the Cochrane guidelines, a $\kappa$ value can quantitatively assess the agreement between two reviewers [10]. As such, values between 0.40 and 0.59 were considered to represent fair agreement, those between 0.60 and 0.74 represented good agreement, and those that were 0.75 or higher represented excellent agreement [8].

2.3. Primary and Secondary Outcomes. The primary outcomes for this meta-analysis were long-term freedom from atrial fibrillation at 12 -month follow-up and overall postoperative complication rates. The secondary outcomes for this review were procedure time, fluoroscopy time, and ablation time.

2.4. Data Management and Extraction. For studies that satisfied the inclusion criteria for this meta-analysis, the data was extracted as per a standardized data extraction form. The data extraction form was first created and piloted by an independent reviewer. The form was used to collect information related to the location of where the study was performed, the various follow-up times, the data reported for the prespecified outcomes, and any miscellaneous outcome information that was not intended to be analyzed by our review. Any data that was reported exclusively in graphical form was extracted using a graph-digitizing software (GraphClick, Arizona Software).

2.5. Assessment of Methodological Quality and Risk of Bias. The Cochrane Collaboration's tool for assessing risk of bias [10] was used by two independent reviewers to evaluate the methodological quality of each included trial. This tool included questions related to randomization, blinding, and outcome data reporting. For each question, the risk of bias was reported as low risk, unclear risk, or high risk of bias. The initial agreement between the reviewers was assessed through the calculation of an unweighted $\kappa$. Again, $\kappa$ values between 0.40 and 0.59 were considered to represent fair agreement, those between 0.60 and 0.74 represented good agreement, and those that were 0.75 or higher represented excellent agreement [10]. In certain situations, the authors of included articles were contacted to elaborate on the methodology used during their research. This was done in order to obtain additional information and to ensure an accurate quality assessment.

2.6. Statistical Analyses and Measurement of Treatment Effect. The primary outcomes of freedom from atrial fibrillation at 12-month follow-up and overall complications are dichotomous variables. As such, an odds ratio (OR) with a 95\% confidence interval (CI) was calculated for these outcomes.

On the other hand, all secondary outcomes were measured in units of time. All time measures were first

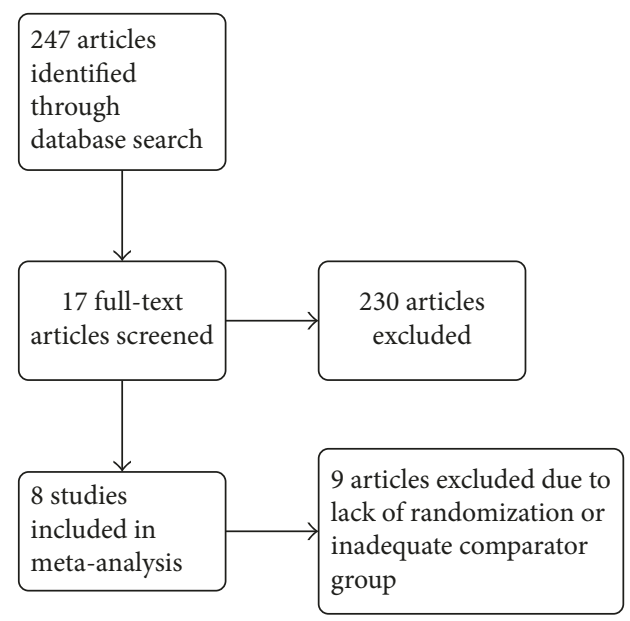

FIGURE 1: Flow diagram of study inclusion.

standardized to a total in minutes. In situations where a median and interquartile range (IQR) were reported, statistical conversions were made to a mean and standard deviation (SD) using the methods described by Wan et al. [11]. In situations where a mean and confidence interval (CI) were reported, statistical conversions were made to a mean and SD using the methods described by the Cochrane Collaboration [12]. Overall, a mean difference (MD) in the unit of minutes with a $95 \%$ CI was calculated for all secondary outcomes.

In situations where data could be pooled, a metaanalysis was performed using the Mantel-Haenszel random-effects model since there was expected heterogeneity between the included studies. $p$ values less than 0.05 were considered to be significant. For continuous outcomes, an MD value less than 0 represented a decrease in value in the specific outcome (e.g., time of procedure, ablation time, or fluoroscopy time) when cryoballoon was used. On the other hand, an MD value greater than 0 represented a gain in value of the specific variable with cryoballoon use.

2.7. Assessment of Heterogeneity. To calculate heterogeneity, an $I^{2}$ statistic test was used. The threshold for conducting subgroup analyses was an $I^{2}$ greater than $40 \%$. As suggested by the Cochrane Handbook for Systematic Reviews, an $I^{2}$ greater than $40 \%$ suggests that heterogeneity may be present [10]. If heterogeneity was present, a priori subgroup analysis was performed on the basis of overall study quality and type of radiofrequency ablation used (Duty Cycle Radiofrequency Ablation versus Irrigated Radiofrequency Energy). Subgroups were only created if more than two studies fell into a specific subgroup. Sensitivity analysis was performed by sequentially removing studies in which a different type of radiofrequency ablation was used.

2.8. Assessment of Publication Bias. A funnel plot was created for the primary outcomes and was visually inspected to assess for publication bias. As per the Cochrane guidelines, 
TABLE 2: Study characteristics.

\begin{tabular}{|c|c|c|c|c|c|c|c|}
\hline Study & Country & $\begin{array}{l}\text { Sample } \\
\text { size }\end{array}$ & Mean age (SD) & $\begin{array}{l}\text { Intervention } \\
\text { (sample size) }\end{array}$ & Comparison & $\begin{array}{c}\text { Mean } \\
\text { follow-up } \\
\text { time }\end{array}$ & Outcomes assessed \\
\hline $\begin{array}{l}\text { Pérez- } \\
\text { Castellano } \\
\text { et al. [13] }\end{array}$ & Spain & 50 & $\begin{array}{l}C B=58(45,62) \\
I R F=56(40,61)\end{array}$ & $\begin{array}{l}\text { Irrigated radiofrequency } \\
\text { energy }(n=25)\end{array}$ & $\begin{array}{l}\text { Cryoballoon } \\
\quad(n=25)\end{array}$ & 12 months & $\begin{array}{l}\text { (i) Freedom from atrial } \\
\text { fibrillation, ablation } \\
\text { time, procedure time, } \\
\text { fluoroscopy time, } \\
\text { complications }\end{array}$ \\
\hline $\begin{array}{l}\text { Herrera } \\
\text { Siklódy } \\
\text { et al. [15] }\end{array}$ & France & 60 & $\begin{aligned} \mathrm{CB} & =57(8) \\
\mathrm{IRF} & =56(10)\end{aligned}$ & $\begin{array}{l}\text { Irrigated radiofrequency } \\
\text { energy }(n=30)\end{array}$ & $\begin{array}{l}\text { Cryoballoon } \\
\quad(n=30)\end{array}$ & 12 months & $\begin{array}{l}\text { (i) Freedom from atrial } \\
\text { fibrillation, procedure } \\
\text { time, fluoroscopy time, } \\
\text { complications, } \\
\text { biochemical response }\end{array}$ \\
\hline $\begin{array}{l}\text { Pokushalov } \\
\text { et al. [14] }\end{array}$ & Russia & 80 & $\begin{aligned} \mathrm{CB} & =56(9) \\
\mathrm{IRF} & =56\end{aligned}$ & $\begin{array}{l}\text { Irrigated radiofrequency } \\
\text { energy }(n=40)\end{array}$ & $\begin{array}{l}\text { Cryoballoon } \\
\quad(n=40)\end{array}$ & 12 months & $\begin{array}{l}\text { (i) Freedom from atrial } \\
\text { fibrillation, procedure } \\
\text { time, fluoroscopy time, } \\
\text { complications }\end{array}$ \\
\hline $\begin{array}{l}\text { Hunter } \\
\text { et al. [16] }\end{array}$ & $\begin{array}{l}\text { United } \\
\text { Kingdom }\end{array}$ & 234 & $\begin{array}{c}\mathrm{CB}=56(11) \\
\mathrm{IRF}=61(12) \\
\text { Combined }=58(12)\end{array}$ & $\begin{array}{c}\text { Irrigated radiofrequency } \\
\text { energy }(n=77) \\
\text { Combined }(n=79)\end{array}$ & $\begin{array}{l}\text { Cryoballoon } \\
\quad(n=78)\end{array}$ & 12 months & $\begin{array}{l}\text { (i) Freedom from atrial } \\
\text { fibrillation, procedure } \\
\text { time, fluoroscopy time, } \\
\text { complications }\end{array}$ \\
\hline $\begin{array}{l}\text { Schmidt } \\
\text { et al. [17] }\end{array}$ & Germany & 99 & $\begin{aligned} \mathrm{CB} & =66(10) \\
\mathrm{IRF} & =63(10) \\
\mathrm{LB} & =65(8)\end{aligned}$ & $\begin{array}{l}\text { Irrigated radiofrequency } \\
\text { energy }(n=33) \\
\text { Laser balloon }(n=33)\end{array}$ & $\begin{array}{l}\text { Cryoballoon } \\
\quad(n=33)\end{array}$ & Postoperative & $\begin{array}{l}\text { (i) Asymptomatic } \\
\text { cerebral lesions } \\
\text { procedure time }\end{array}$ \\
\hline $\begin{array}{l}\text { Kuck et al. } \\
{[6]}\end{array}$ & Germany & 750 & $\begin{array}{l}\mathrm{CB}=59.9(9.8) \\
\mathrm{IRF}=60.1(9.2)\end{array}$ & $\begin{array}{l}\text { Irrigated radiofrequency } \\
\text { energy }(n=376)\end{array}$ & $\begin{array}{l}\text { Cryoballoon } \\
(n=374)\end{array}$ & 1.5 years & $\begin{array}{l}\text { (i) Recurrence of atrial } \\
\text { fibrillation, procedure } \\
\text { time, fluoroscopy time, } \\
\text { complications }\end{array}$ \\
\hline $\begin{array}{l}\text { Luik et al. } \\
\text { [5] }\end{array}$ & Germany & 215 & $\begin{aligned} \mathrm{CB} & =61(54,66) \\
\mathrm{IRF} & =60(54,67)\end{aligned}$ & $\begin{array}{l}\text { Irrigated radiofrequency } \\
\text { energy }(n=159)\end{array}$ & $\begin{array}{l}\text { Cryoballoon } \\
(n=141)\end{array}$ & 12 months & $\begin{array}{l}\text { (i) Freedom from atrial } \\
\text { fibrillation, } \\
\text { complications }\end{array}$ \\
\hline $\begin{array}{l}\text { Malmborg } \\
\text { et al. [18] }\end{array}$ & Sweden & 110 & $\begin{array}{c}\mathrm{CB}=59(9) \\
\mathrm{PDRF}=62(7)\end{array}$ & $\begin{array}{l}\text { Phased duty-cycled } \\
\text { radiofrequency energy } \\
(n=56)\end{array}$ & $\begin{array}{l}\text { Cryoballoon } \\
\quad(n=54)\end{array}$ & 12 months & $\begin{array}{l}\text { (i) Freedom from atrial } \\
\text { fibrillation, ablation } \\
\text { time, procedure time, } \\
\text { fluoroscopy time, } \\
\text { complications, quality } \\
\text { of life }\end{array}$ \\
\hline
\end{tabular}

in the absence of bias, the plot should generally take the shape of a symmetrical, inverted funnel.

2.9. Data Management. All forest and funnel plots were generated using Review Manager software (RevMan version 5.2; Nordic Cochrane Centre, Cochrane Collaboration). Agreement between the reviewers, as assessed through the unweighted $\kappa$, was calculated using SPSS software (version 21.0; SPSS Inc.). Finally, all tests of significance were two-tailed and $p$ values less than 0.05 were considered significant.

\section{Results}

3.1. Study Inclusion. A total of 247 articles were identified by the systematic literature search. After an initial title and abstract screening, a total of 17 were considered and retrieved to assess their eligibility by review of the full text. Of these articles, a total of eight satisfied the prespecified inclusion criteria and were included in this review $[5,6,13-18]$. A flow diagram of study inclusion can be viewed in Figure 1. Articles were excluded if they were nonrandomized or lacked an adequate comparison group. The raw agreement between the independent reviewers for full eligibility was $88.2 \%$ and the unweighted $\kappa$ was calculated to be 0.75 , which represents good agreement between the two reviewers.

3.2. Study Characteristics. A detailed description of all the included studies can be viewed in Table 2. A total of eight studies encompassing 1548 patients undergoing either cryoballoon or radiofrequency ablation were included. All of the included studies were published between the years 2012 and 2015. Studies were conducted at centers across continental Europe, the United Kingdom, and Russia. Seven of the included studies had published study protocols available for review [5, 6, 13-17]. Seven of the studies compared cryoballoon with irrigated radiofrequency energy ablation 
$[5,6,13-17]$, whereas one made the comparison with phased duty-cycled radiofrequency energy ablation [18].

3.3. Risk of Bias Assessment. The majority of studies had a low risk or unclear risk of bias for several methodological parameters as assessed through the Cochrane tool for risk of bias assessment (Figure 2). Only one study sufficiently reported information on the blinding of study participants and personnel [16]. Visual inspection of the funnel plot for all primary outcomes (freedom from atrial fibrillation and overall complication rate) did not suggest publication bias; however, there were few studies with large effect sizes (Figures 3 and 4). Thus, publication bias cannot be entirely ruled out.

3.4. Freedom from Atrial Fibrillation at Long-Term Follow-Up. A total of eight studies assessed freedom from atrial fibrillation at $\geq 12$-month follow-up $(n=1542)[5,6,13-18]$. Across these studies, 53\% (393/741) of patients receiving cryoballoon ablation and 53\% (399/751) of patients receiving radiofrequency ablation developed atrial fibrillation at $\geq 12$-month follow-up. Overall, it was found that there was no significant difference in freedom from atrial fibrillation at $\geq 12$-month follow-up between those who received cryoballoon ablation and those who received radiofrequency ablation $(\mathrm{OR}=0.98, \quad \mathrm{CI}=0.67-1.43$, $\left.I^{2}=56 \%, p=0.90\right)$ (Figure 5). These results were robust to sensitivity analysis as the removal of one study which utilized phase duty-cycled radiofrequency ablation did not alter the results $\left(\mathrm{OR}=0.90, \mathrm{CI}=0.60-1.36, I^{2}=58 \%\right.$, $p=0.62$ ).

3.5. Procedure Duration. Eight studies assessed the procedure time $(n=1582)[5,6,13-18]$. The weighted mean procedure duration using cryoballoon ablation and radiofrequency ablation was found to be 161.79 minutes in comparison to 165.87 for radiofrequency ablation. Overall, cryoballoon ablation was found to be 4.08 minutes shorter; however, this difference failed to reach significance $(\mathrm{MD}=-4.08, \mathrm{CI}=-19.47-11.30$, $I^{2}=89 \%, p=0.60$ ) (Figure 6). These findings were robust to sensitivity analysis as nonsignificance remained (MD: -4.20 , $\mathrm{CI}=-21.75-13.36, I^{2}=91 \%, p=0.64$ ) even after removal of the data from the one study that utilized phase duty-cycled radiofrequency ablation.

3.6. Fluoroscopy Time. A total of six studies assessed fluoroscopy time $(n=1204)[6,13-16,18]$. The weighted mean fluoroscopy time was found to be 33.11 minutes with cryoballoon ablation and 31.94 minutes with radiofrequency ablation. Although using cryoballoon ablation prolonged fluoroscopy time by 1.17 minutes, this result failed to reach significance when compared to radiofrequency ablation $\left(\mathrm{MD}=1.17, \mathrm{CI}=-4.94-7.28, I^{2}=87 \%, p=0.71\right)$ (Figure 7). Sensitivity analysis revealed a significant prolongation of fluoroscopy time by 5.07 minutes when the data from the phased duty-cycled ablation was removed and cryoballoon

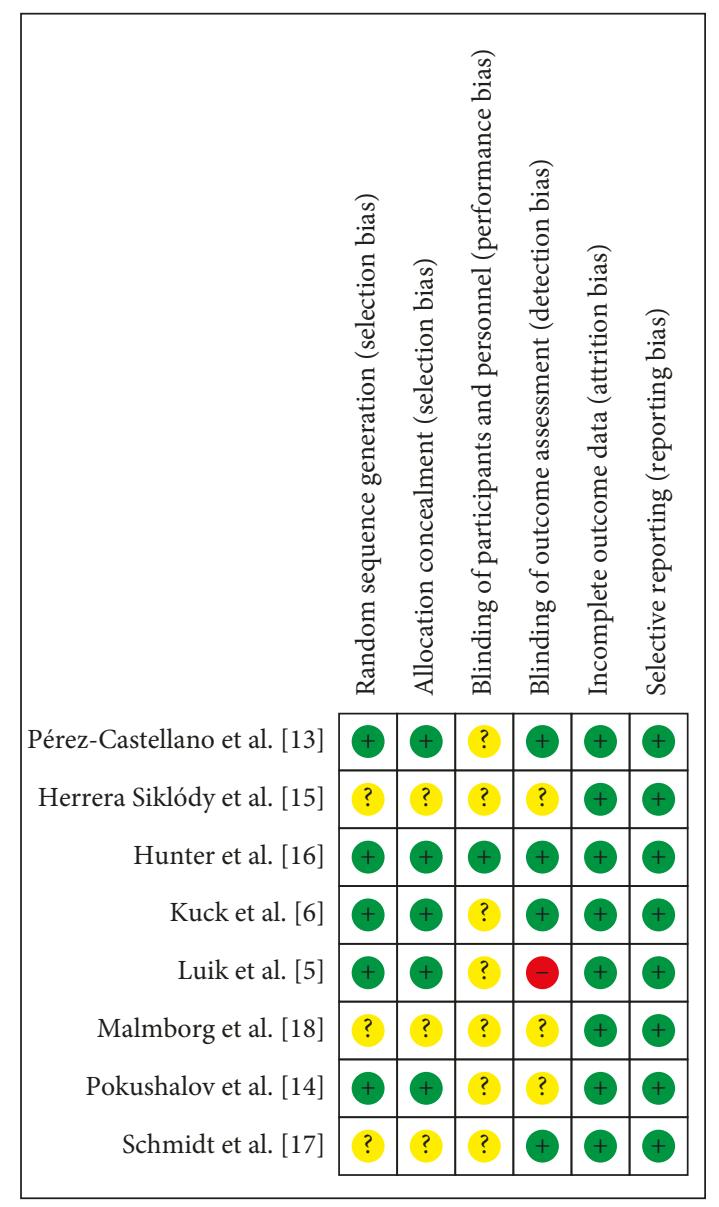

FIgURE 2: Risk of bias of included studies in the meta-analysis.

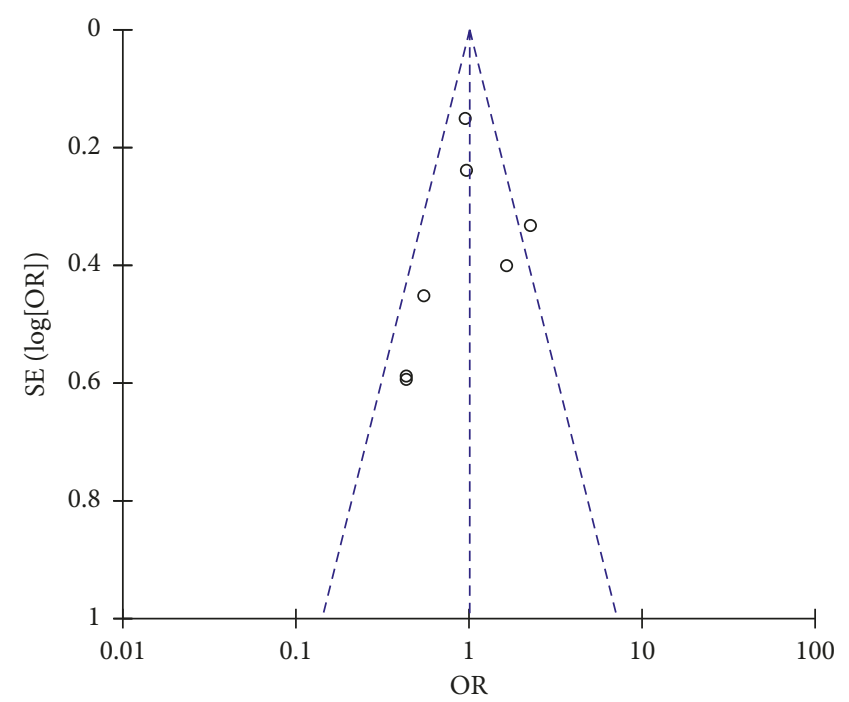

Figure 3: Funnel plot for assessment of publication bias for freedom from atrial fibrillation at 12-month follow-up.

was compared with irrigated radiofrequency energy ablation in isolation $\left(\mathrm{MD}=5.07, \mathrm{CI}=3.21-6.93, I^{2}=0 \%\right.$, $p<0.00001)$. 


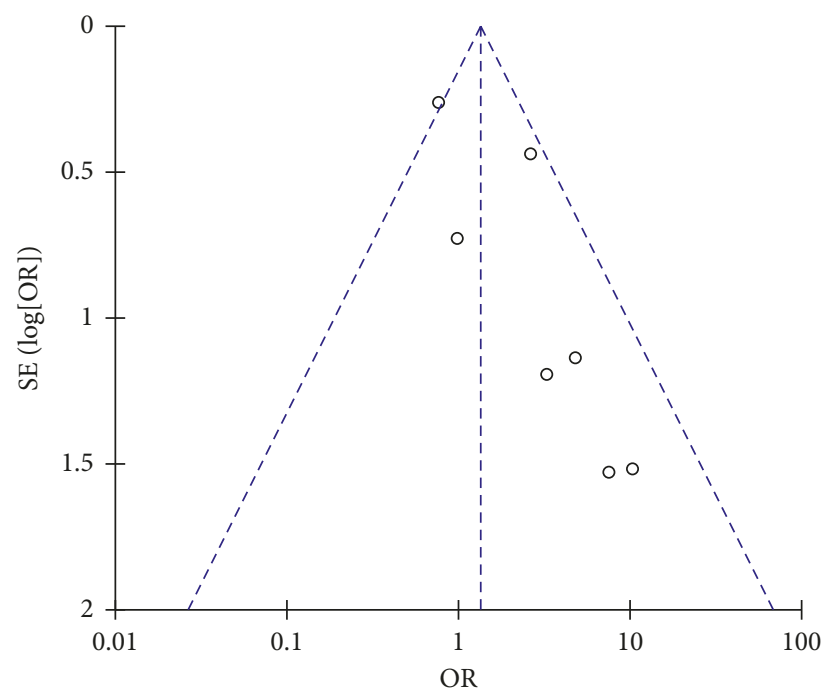

FIGURE 4: Funnel plot for overall postoperative complication rate.

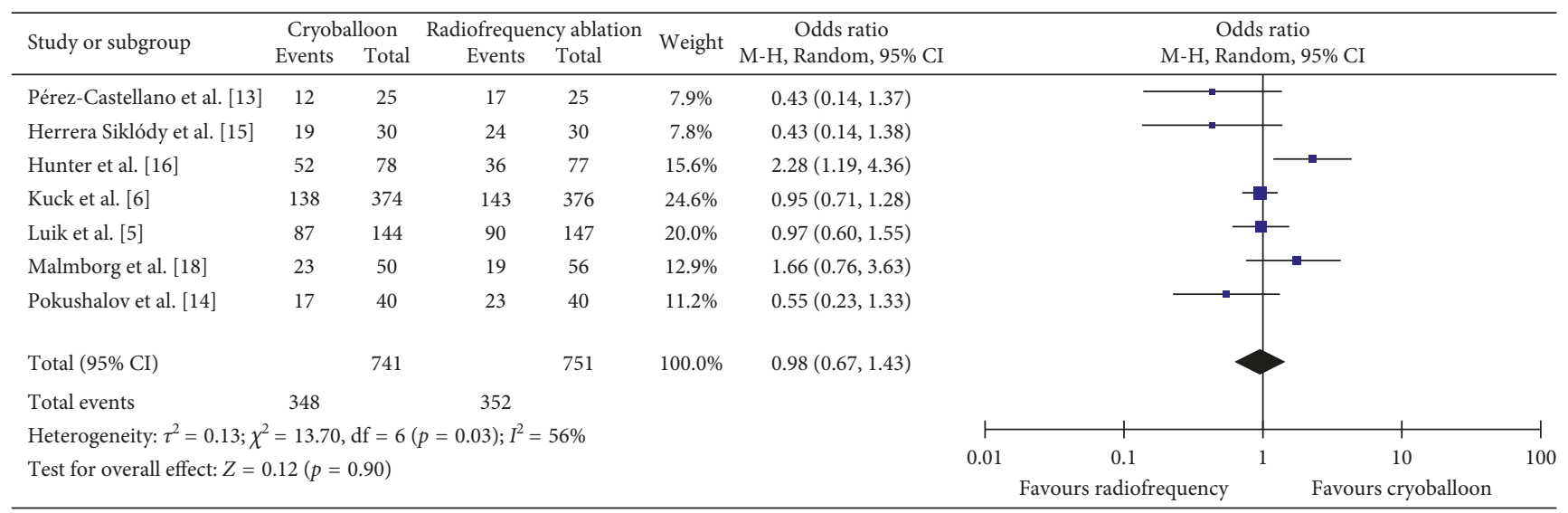

FIGURE 5: Mean odds ratio with $95 \%$ CI of patients free from atrial fibrillation at $\geq 12$-month follow-up.

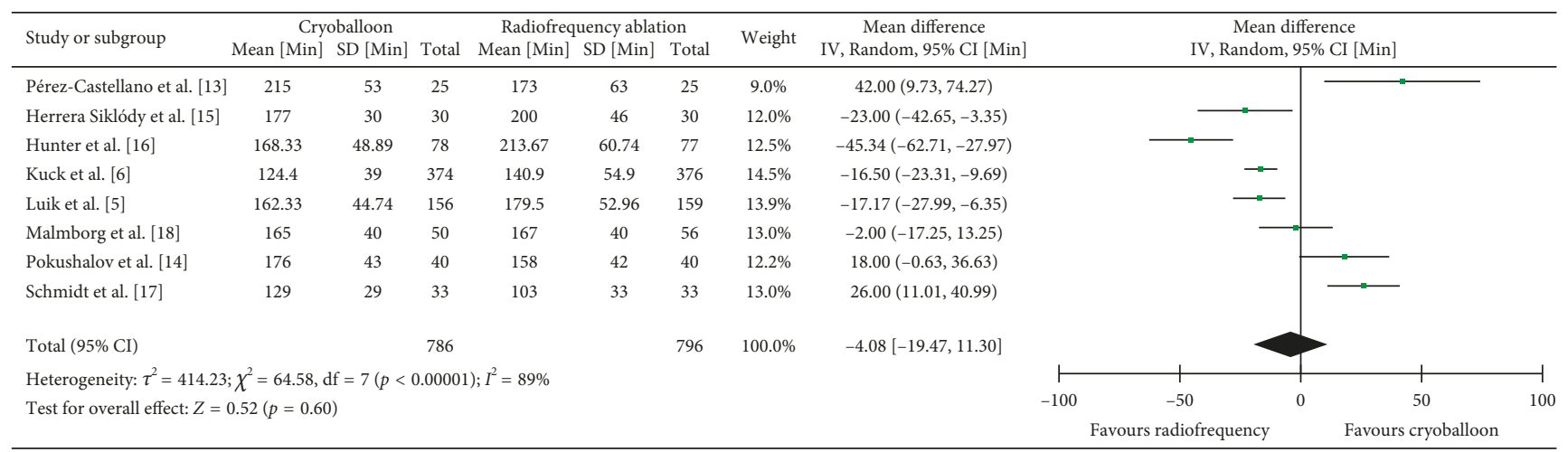

FIGURE 6: Mean procedure time in minutes with 95\% CI of patients receiving cryoballoon versus radiofrequency ablation.

3.7. Ablation Time. Two studies assessed ablation time $(n=155)[13,18]$. The weighted mean ablation time was found to be 99.02 minutes with cryoballoon ablation and 91.06 minutes with radiofrequency ablation. Overall, although ablation time was 7.97 minutes longer with cryoballoon ablation, no significant difference was observed when compared with radiofrequency ablation $(\mathrm{MD}=7.97, \mathrm{CI}=-35.15-51.09$, $I^{2}=95 \%, p=0.72$ ) (Figure 8). Sensitivity and subgroup 


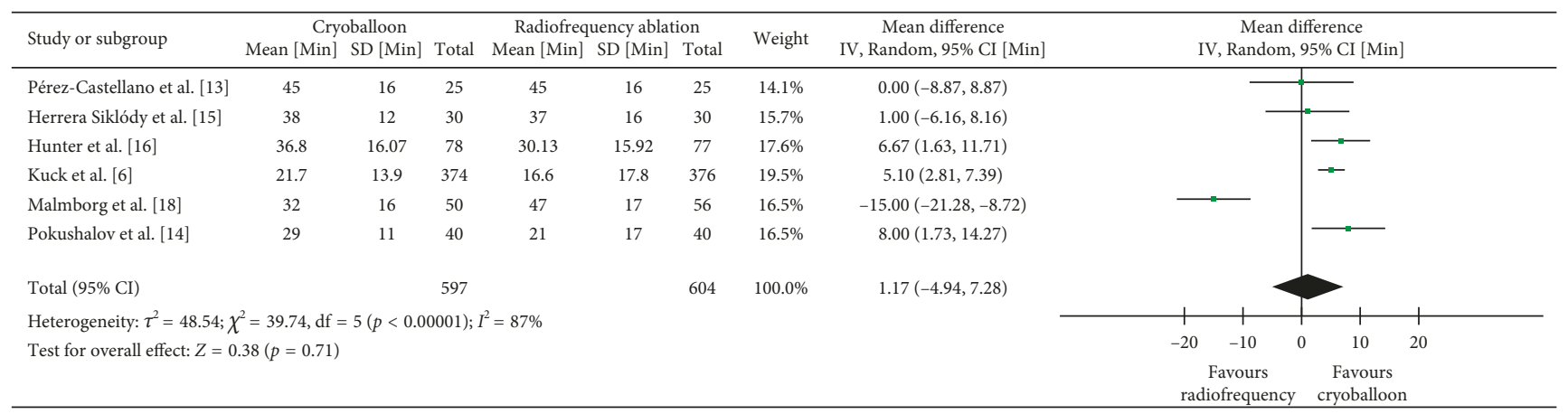

Figure 7: Mean fluoroscopy time in minutes with $95 \% \mathrm{CI}$ in patients receiving cryoballoon versus radiofrequency ablation.

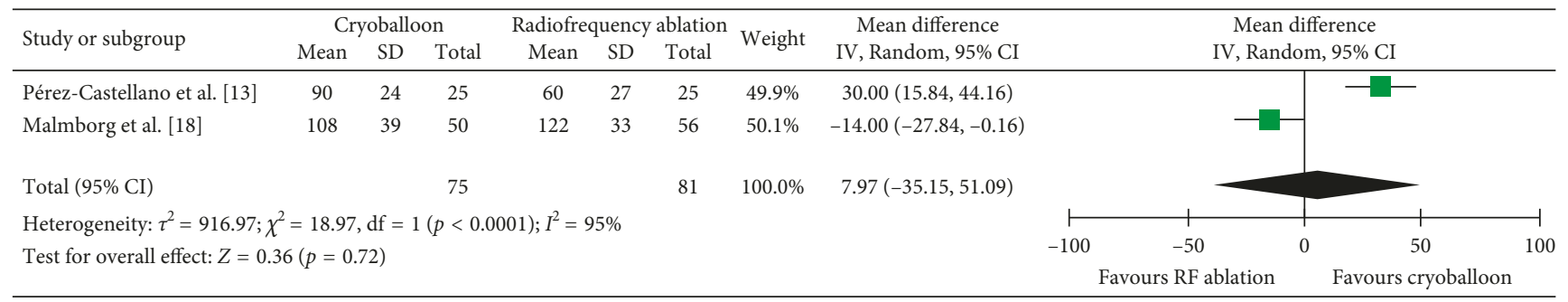

Figure 8: Mean ablation time in minutes with $95 \%$ CI in patients receiving cryoballoon versus radiofrequency ablation.

analysis was not performed due to the limited number of studies in this outcome.

3.8. Postoperative Complications. Seven studies reported complications associated with both radiofrequency and cryoballoon ablation $(n=1492)[5,6,13-16,18]$. A list of all complications reported by the included studies in this meta-analysis can be viewed in Table 3. Irrespective of the type of complication and the transient nature of the complication, cryoballoon ablation was found to have a 1.90 times greater odds of having a complication in comparison to radiofrequency ablation; however, this difference failed to reach significance $(\mathrm{OR}=1.90, \mathrm{CI}=0.88-4.11$, $I^{2}=50 \%, p=0.10$ ) (Figure 9). These findings were unaltered by sensitivity analysis $\left(\mathrm{OR}=1.73, \mathrm{CI}=0.77-3.89, I^{2}=53 \%\right.$, $p=0.18)$.

We further stratified the overall complication rate based on the type of complication reported. Overall, it was found that cryoballoon ablation had a 10.3 times greater odds of postoperative phrenic nerve injury at 12 -month follow-up in comparison to radiofrequency ablation alone $(\mathrm{OR}=10.3$, $\mathrm{CI}=3.09$ to $\left.34.6, I^{2}=0 \%, p=0.0001\right)[5,6,14-16,18]$. Five of these studies reported that phrenic injury was transient and resolved at 12-month follow-up [5, 14-16, 18]; one study reported permanent phrenic nerve injury in one patient [6]. In regards to cardiac tamponade, the odds of this complication did not significantly differ between cryoballoon and radiofrequency ablation $[5,6,16](\mathrm{OR}=0.39, \mathrm{CI}=0.11-1.40$, $\left.I^{2}=0 \%, p=0.15\right)$. A nonsignificant difference in risk favoring cryoballoon was also seen with the outcome of postoperative atrial flutter $[6,13,15](\mathrm{OR}=0.63, \mathrm{CI}=0.10$ to $\left.4.15, I^{2}=57 \%, p=0.63\right)$.

\section{Discussion}

In the present meta-analysis, we found no difference in the freedom from atrial fibrillation at 12 months between patients randomized to cryoballoon and those randomized to radiofrequency catheter ablation of atrial fibrillation. These results are consistent with recently published data from the Fire and ICE study [6]. Although patients undergoing cryoballoon ablation had shorter total procedure duration when compared to RF ablation by a mean of 4 mins, this difference did not reach statistical difference in the hands of experienced operators. RF ablation requires point-by-point circumferential ablation around pulmonary veins and may be more time consuming and technically challenging for new operators.

The fluoroscopy time was prolonged in cryoballoon ablation group by a mean of 1.17 minutes, but this small difference was not statistically significant. We found that there was a higher risk of postprocedure atrial flutter in the RF group, which was not significant.

There was a significantly higher incidence of phrenic nerve injury with cryoablation; however, most of these injuries resolved at 12 months. Thus, there was no difference in the risk of persistent phrenic nerve injury at 12 months. Phrenic nerve injury is a common concern during cryoballoon ablation of AF. Although the risk of transient phrenic nerve injury was almost ten times higher in cryoballoon group, only one patient in one study had persistent injury at 12 months of follow-up. Thus, the risk of permanent phrenic injury was low in the cryoballoon group as well.

Pulmonary vein isolation using RF energy utilizes pointby-point wide circumferential lesion. This wide area ablation can sometimes result in creating a substrate for postablation 
TABLE 3: Reported postoperative complications after cryoballoon ablation versus radiofrequency ablation.

\begin{tabular}{|c|c|c|c|c|}
\hline \multirow[b]{2}{*}{ Study } & \multicolumn{2}{|c|}{ Cryoballoon ablation } & \multicolumn{2}{|c|}{ Radiofrequency ablation } \\
\hline & Complication & $\begin{array}{c}\text { Number of patients } \\
(n=741)\end{array}$ & Complication & $\begin{array}{c}\text { Number of patients } \\
(n=751)\end{array}$ \\
\hline $\begin{array}{l}\text { Pérez-Castellano } \\
\text { et al. [13] }\end{array}$ & Hemoptysis & 1 & $\begin{array}{l}\text { Right femoral arteriovenous } \\
\text { fistula }\end{array}$ & 1 \\
\hline \multirow{3}{*}{$\begin{array}{l}\text { Herrera Siklódy et al. } \\
{[15]}\end{array}$} & Phrenic nerve injury & 2 & & \\
\hline & Femoral pseudoaneurysm & 1 & & \\
\hline & Groin hematoma & 1 & & \\
\hline \multirow{4}{*}{ Hunter et al. [16] } & Phrenic nerve injury & 4 & Tamponade & 1 \\
\hline & & & Hematoma & 1 \\
\hline & & & $\begin{array}{l}\text { Asymptomatic pulmonary vein } \\
\text { stenosis }\end{array}$ & 1 \\
\hline & & & Dressler's syndrome & 1 \\
\hline \multirow{10}{*}{ Kuck et al. [6] } & Phrenic nerve injury & 10 & Groin site complication* & 16 \\
\hline & Groin site complication* & 7 & $\begin{array}{c}\text { Cardiac tamponade/pericardial } \\
\text { effusion }\end{array}$ & 5 \\
\hline & $\begin{array}{l}\text { Other, nonarrhythmia } \\
\text { complications** }\end{array}$ & 3 & Pulmonary complication & 4 \\
\hline & Pulmonary complication & 2 & $\begin{array}{l}\text { Transient neurological } \\
\text { complication }\end{array}$ & 3 \\
\hline & $\begin{array}{c}\text { Cardiac tamponade/pericardial } \\
\text { effusion }\end{array}$ & 1 & Dyspnea & 2 \\
\hline & $\begin{array}{l}\text { Transient neurological } \\
\text { complication }\end{array}$ & 1 & Gastrointestinal complication & 2 \\
\hline & Dyspnea & 1 & Contrast media reaction & 1 \\
\hline & Anxiety & 1 & Contusion & 1 \\
\hline & Esophageal ulcer & 1 & Hematuria & 1 \\
\hline & Gastrointestinal complication & 1 & Local edema & 1 \\
\hline \multirow{3}{*}{ Luik et al. [5] } & Phrenic nerve injury & 9 & Vascular & 5 \\
\hline & Vascular & 8 & Pericardial effusion & 3 \\
\hline & Pericardial effusion & 2 & & \\
\hline \multirow{2}{*}{ Malmborg et al. [18] } & Groin hematoma & 2 & Groin hematoma & 1 \\
\hline & Phrenic nerve injury & 2 & & \\
\hline Pokushalov et al. [14] & Phrenic nerve injury & 3 & & \\
\hline Total patients & & 65 & & 50 \\
\hline
\end{tabular}

${ }^{*}$ As per the study, groin site complications included vascular pseudoaneurysm, arteriovenous fistula, device-related infection, hematoma, puncture site hemorrhage, and groin pain. ${ }^{* *}$ As per the study, other cardiac complications included atrial septal defects, coronary artery disease, and pericarditis.

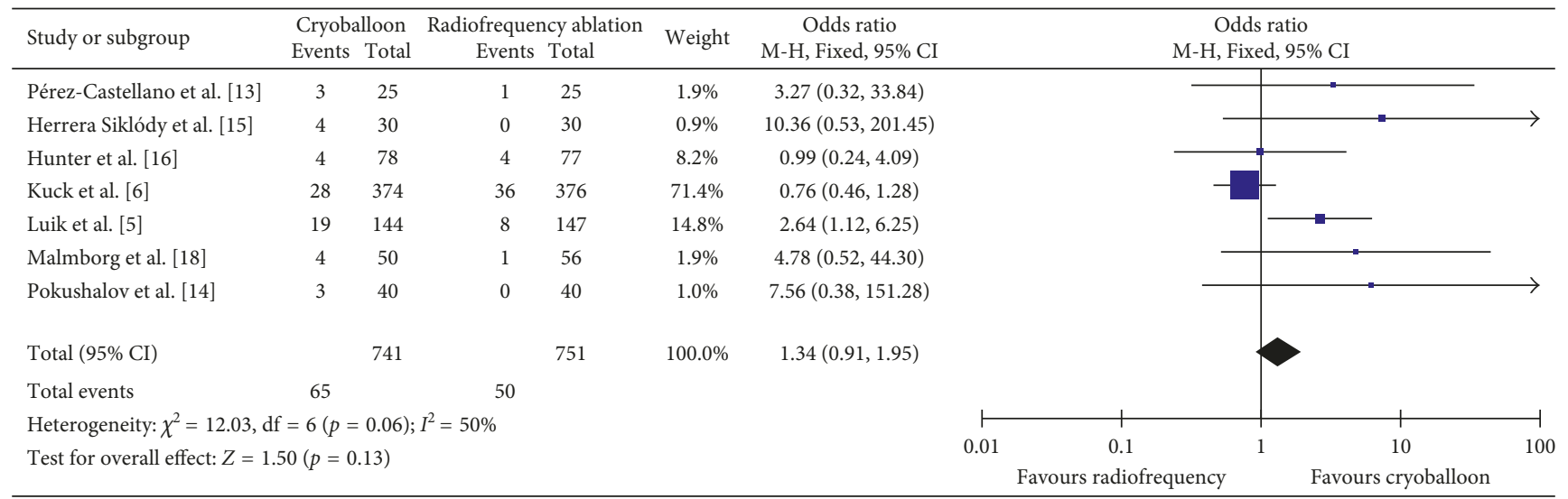

Figure 9: Mean odds ratio of overall postoperative complications with $95 \% \mathrm{CI}$ in patients receiving cryoballoon versus radiofrequency ablation. 
atrial flutter. Potentially, RF ablation should be associated with higher risk of postablation atrial flutter; however, in our analysis, the risk of atrial flutter was not significantly different in the two groups.

In this analysis, we found no significant differences in the overall success, fluoroscopy times, total ablation times, procedure times, and any complications seen in the two groups. Cryoballoon has become increasingly used over last few years due to several potential advantages. The need of a single transseptal puncture for cryoballoon is a definite advantage, although some centers perform RF ablation using a single transseptal catheterization as well. The learning curve for cryoablation may also be shorter.

Our analysis provides some important results, but several important questions remain unanswered. In recent years, force-sensing catheters have been used increasingly for RF ablation. These catheters provide real-time information about the catheter contact with the tissue and thus may improve the effectiveness of delivered RF lesions. We have no data systematically comparing force-sensing $\mathrm{RF}$ catheters verses cryoballoon ablation. A recent study showed no differences in the long-term outcomes when contact force information was available to the operators [19]. Our analysis included studies including both first- and second-generation cryoballoon. There was only one multicenter randomized study comparing radiofrequency ablation with contact force sense catheters with secondgeneration cryoballoon and found no difference in the outcomes following ablation using either strategy [20]. We also do not have information about patients in whom cryoballoon ablation was attempted but PVI was either not achieved or not attempted because of unsuitable anatomy.

The fluoroscopy times were found to be higher in the cryoballoon group. Although not statistically significant, this difference may become more relevant in the future as more centers are utilizing advanced mapping technology coupled with intracardiac echocardiography to minimize or eliminate the use of fluoroscopy during RF ablation. There is a need for devising strategies to minimize the use of fluoroscopy in patients undergoing cryoballoon ablation in the future. Monitoring for recurrence of atrial fibrillation after ablation was performed either using an implantable loop recorder or a Holter monitor for two to seven days at 3,6 , and 12 months of the follow-up.

\section{Conclusions}

In conclusion, the results of this meta-analysis reveal similar overall success rates at 12 months and comparable fluoroscopy and procedural times and long-term complications between patients undergoing cryoballoon and RF ablation for AF ablation. Given similar outcomes, operators should choose AF ablation technology based on patient-specific features and preferences as well as operator experience and preference.

\section{Conflicts of Interest}

The authors declare that they have no conflicts of interest.

\section{Authors' Contributions}

Ali H. Hachem, Joseph E. Marine, and Khalil Kanjwal were responsible for study conception and design, acquisition of data, analysis and interpretation of date, drafting of manuscript, and critical revision. Housam A. Tahboub, Sana Kamdar, Shaffi Kanjwal, and Ronak Soni were responsible for acquisition of data, analysis of data, drafting of manuscript, and manuscript critical revision.

\section{References}

[1] A. J. Camm, G. Y. H. Lip, R. De Caterina et al., "2012 focused update of the ESC Guidelines for the management of atrial fibrillation," European Heart Journal, vol. 33, no. 21, pp. 2719-2747, 2012.

[2] L. Carter, M. Gardner, K. Magee et al., "An integrated management approach to atrial fibrillation," Journal of the American Heart Association, vol. 5, no. 1, p. e002950, 2016.

[3] J. W. Magnani, M. Rienstra, H. Lin et al., "Atrial fibrillation: current knowledge and future directions in epidemiology and genomics," Circulation, vol. 124, no. 18, pp. 1982-1993, 2011.

[4] A. Skelly, R. Hashimoto, S. Al-Khatib et al., Catheter Ablation for Treatment of Atrial Fibrillation, Agency for Healthcare Research and Quality, Rockville, MD, USA, 2015, http://www. ncbi.nlm.nih.gov/books/NBK305760.

[5] A. Luik, A. Radzewitz, M. Kieser et al., "Cryoballoon versus open irrigated radiofrequency ablation in patients with paroxysmal atrial fibrillation: the prospective, randomized, controlled, noninferiority freeze AF study," Circulation, vol. 132, no. 14, pp. 1311-1319, 2015.

[6] K.-H. Kuck, J. Brugada, A. Fürnkranz et al., "Cryoballoon or radiofrequency ablation for paroxysmal atrial fibrillation," New England Journal of Medicine, vol. 374, no. 23, pp. 2235-2245, 2016.

[7] H. F. Tse, S. Reek, C. Timmermans et al., "Pulmonary vein isolation using transvenous catheter cryoablation for treatment of atrial fibrillation without risk of pulmonary vein stenosis," Journal of the American College of Cardiology, vol. 42, no. 4, pp. 752-758, 2003.

[8] S. Miyazaki, A. Kuroi, H. Hachiya et al., "Early recurrence after pulmonary vein isolation of paroxysmal atrial fibrillation with different ablation technologies-prospective comparison of radiofrequency vs. second-generation cryoballoon ablation," Circulation Journal, vol. 80, no. 2, pp. 346-353, 2015.

[9] P. Kojodjojo, M. D. O’Neill, P. B. Lim et al., "Pulmonary venous isolation by antral ablation with a large cryoballoon for treatment of paroxysmal and persistent atrial fibrillation: medium-term outcomes and non-randomised comparison with pulmonary venous isolation by radiofrequency ablation," Heart, vol. 96, no. 17, pp. 1379-1384, 2010.

[10] J. P. T. Higgins and S. Green, Cochrane Handbook for Systematic Reviews of Interventions, Version 5.1.0 [updated March 2011], The Cochrane Collaboration 2011, John Wiley \& Sons, Ltd, Hoboken, NJ, USA, 2015, http://handbook.cochrane.org/.

[11] X. Wan, W. Wang, J. Liu, and T. Tong, "Estimating the sample mean and standard deviation from the sample size, median, range and/or interquartile range," BMC Medical Research Methodology, vol. 14, no. 1, p. 135, 2014.

[12] M. J. Bradburn, J. J. Deeks, J. A. Berlin, and R. A. Localio, "Much ado about nothing: a comparison of the performance of meta-analytical methods with rare events," Statistics in Medicine, vol. 26, no. 1, pp. 53-77, 2007. 
[13] N. Pérez-Castellano, R. Fernández-Cavazos, J. Moreno et al., "The COR trial: a randomized study with continuous rhythm monitoring to compare the efficacy of cryoenergy and radiofrequency for pulmonary vein isolation," Heart Rhythm, vol. 11, no. 1, pp. 8-14, 2014.

[14] E. Pokushalov, A. Romanov, S. Artyomenko et al., "Cryoballoon versus radiofrequency for pulmonary vein re-isolation after a failed initial ablation procedure in patients with paroxysmal atrial fibrillation," Journal of Cardiovascular Electrophysiology, vol. 24, no. 3, pp. 274-279, 2013.

[15] C. Herrera Siklódy, T. Arentz, J. Minners et al., "Cellular damage, platelet activation, and inflammatory response after pulmonary vein isolation: a randomized study comparing radiofrequency ablation with cryoablation," Heart Rhythm, vol. 9, no. 2, pp. 189-196, 2012.

[16] R. J. Hunter, V. Baker, M. C. Finlay et al., "Point-by-point radiofrequency ablation versus the cryoballoon or a novel combined approach: a randomized trial comparing 3 methods of pulmonary vein isolation for paroxysmal atrial fibrillation (the cryo versus RF trial)," Journal of Cardiovascular Electrophysiology, vol. 26, no. 12, pp. 1307-1314, 2015.

[17] B. Schmidt, M. Gunawardene, D. Krieg et al., "A prospective randomized single-center study on the risk of asymptomatic cerebral lesions comparing irrigated radiofrequency current ablation with the cryoballoon and the laser balloon," Journal of Cardiovascular Electrophysiology, vol. 24, no. 8, pp. 869-874, 2013.

[18] H. Malmborg, S. Lönnerholm, P. Blomström, and C. BlomströmLundqvist, "Ablation of atrial fibrillation with cryoballoon or duty-recycled radiofrequency pulmonary vein ablation catheter: a randomized controlled study comparing the clinical outcome and safety; the AF-COR study," Europace, vol. 11, pp. 1567-1573, 2015.

[19] W. Ullah, A. McLean, M. H. Tayebjee et al., "Randomized trial comparing pulmonary vein isolation using the SmartTouch catheter with or without real-time contact force data," Heart Rhythm, vol. 13, no. 9, pp. 1761-1767, 2016.

[20] F. Squara, A. Zhao, E. Marijon et al., "Comparison between radiofrequency with contact force-sensing and secondgeneration cryoballoon for paroxysmal atrial fibrillation catheter ablation: a multicentre European evaluation," Europace, vol. 17, no. 5, pp. 718-724, 2015. 


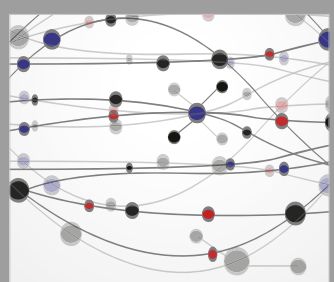

The Scientific World Journal
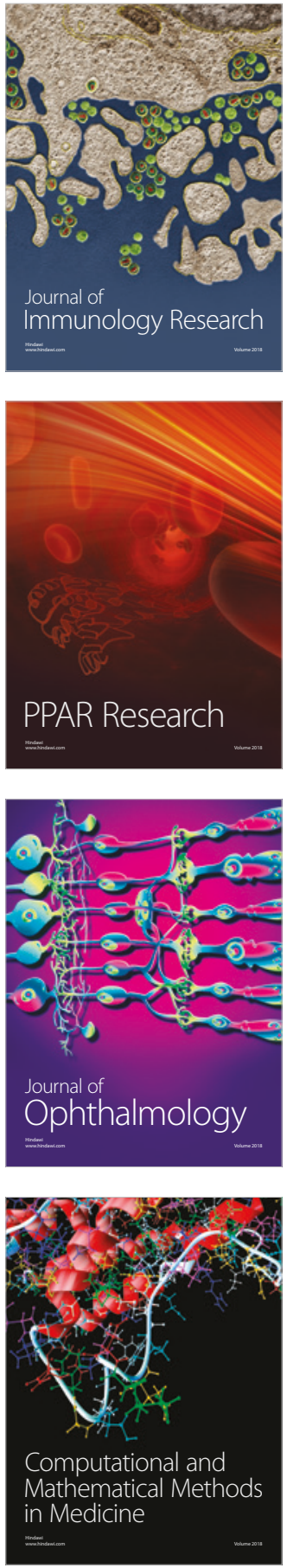

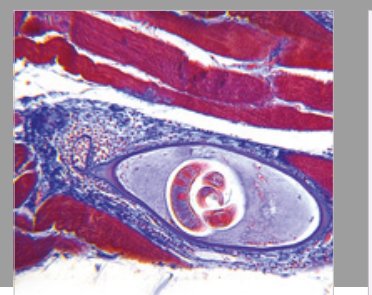

Gastroenterology Research and Practice

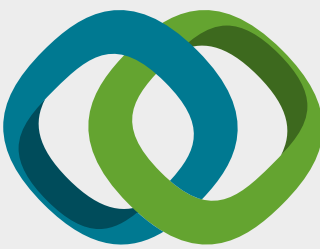

\section{Hindawi}

Submit your manuscripts at

www.hindawi.com
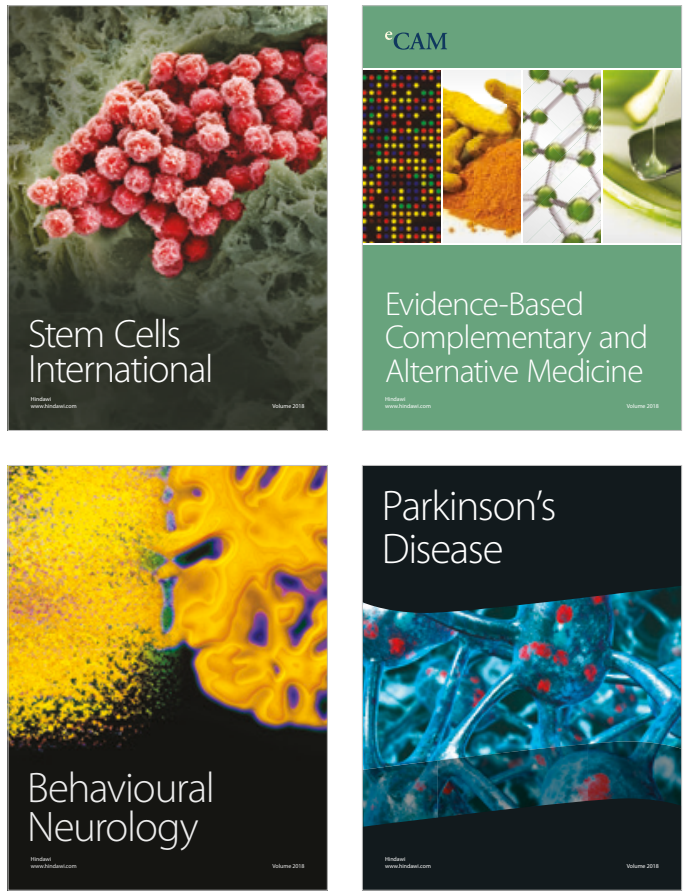

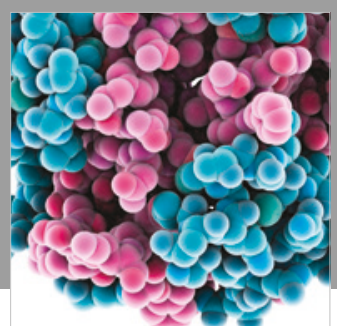

ournal of

Diabetes Research

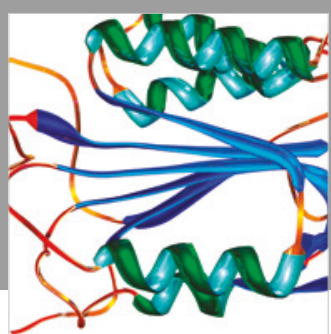

Disease Markers
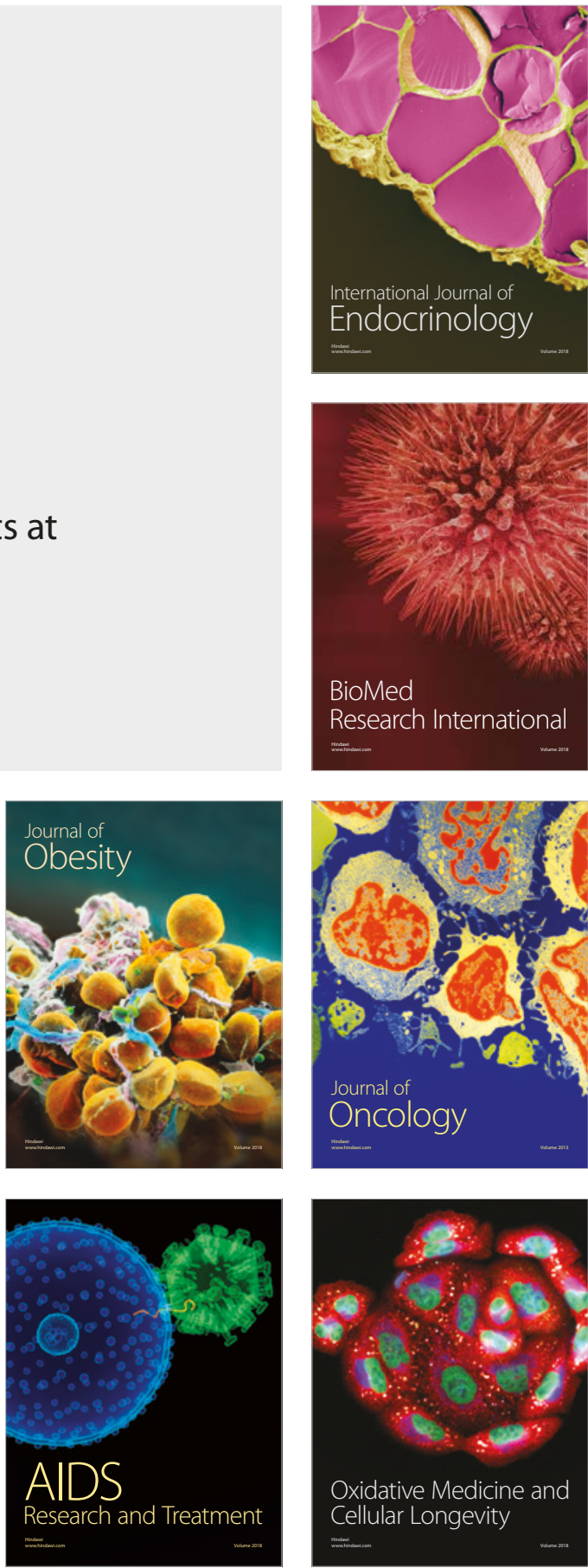